\title{
La alimentación en contextos mineros surandinos: diálogos entre cultura material y evidencia documental (siglos XIX y XX)
}

\author{
Food in South Andean Mining Contexts: \\ Dialogues between Material Culture and \\ Documentary Evidence (19th and 20th centuries) \\ Osvaldo Sironi** \\ Luis Eduardo Mafferra ${ }^{* * *}$ \\ lanigla-Conicet, Argentina
}

D0I: $10.22380 / 2539472 X .1050$

\begin{abstract}
RESUMEN
Este artículo analiza prácticas sociales de alimentación en contextos mineros de plata, oro y esquistos bituminosos del periodo republicano en la precordillera de Mendoza (Argentina). El objetivo es reconstruir la cadena operativa alimentaria y la escala de distribución espaciotemporal de los conjuntos artefactuales de la población, a partir de la integración de seis líneas de evidencia: fuentes documentales, elementos cerámicos, metálicos y vítreos, así como también restos arqueofaunísticos y botánicos. Los resultados sugieren que las fases de la cadena operativa alimentaria se encuentran sub o sobrerrepresentadas, con diferencias entre ambos sitios. Respecto a las escalas de distribución, los sitios estuvieron especialmente insertos en circuitos de circulación de productos regionales y, en menor medida, locales y globales.
\end{abstract}

Palabras clave: antropología de la alimentación, emplazamientos mineros, cadena operativa, escala de distribución.

\begin{abstract}
$\overline{\text { ABSTRACT }}$
This article analyzes social food practices in mining contexts of silver, gold and bituminous shales of the republican period (mid $19^{\text {th }}$ to early $20^{\text {th }}$ century) in the precordillera of Mendoza (Argentina). The objective is to reconstruct the operational food chain of the mining population and the space-time distribution scale of their artifact sets, based on the integration of six lines of evidence: documentary sources, ceramics, metallic and glass elements, as well as archaeozoological and botanical remains. The results suggest that the phases of the operational food chain are under or overrepresented with some differences between the two targeted sites. With respect to the distribution scales, the sites were inserted in circulation circuits of regional products mainly and, to a lesser extent, local and global ones.
\end{abstract}

Keywords: anthropology of food, mining sites, operational chain, distribution scale.

\footnotetext{
* Esta obra está bajo licencia internacional Creative Commons Reconocimiento-NoComercialSinObrasDerivadas 4.0

** Becario posdoctoral del Ianigla-Conicet. osvaldosironi@gmail.com / https://orcid.org/00000002-0986-4871

*** Becario posdoctoral del Ianigla-Conicet. luismafferra@gmail.com / https://orcid.org/00000002-3966-6833
} 


\section{Introducción}

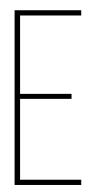

l campo de estudio de la alimentación ha sido poco explorado en la historia y arqueología del centro-oeste argentino, y solo existen trabajos para el sitio Ciudad de Mendoza (siglos XV y XX) (Araújo 2016; Castillo et al. 2018; Mafferra, Sironi y López 2012; Sironi, Mafferra y López 2016). A escala nacional, los aportes son significativos tanto para el periodo colonial y el siglo XIX (Marschoff 2010, 2013, 2014) como para otras áreas temáticas (Babot, Marschoff y Pazzarelli 2012; Pazzarelli 2008, 2010). En relación con los contextos mineros, el problema se encuentra prácticamente inexplorado incluso a escala latinoamericana. A escala regional, existen aportes cercanos ligados al análisis del registro zooarqueológico (Estrella y Gasco 2002; Labarca 2009; Labarca, Calás y Rivera 2010; Sironi et al. 2013), así como estudios tecnotipológicos de materiales vítreos (Sironi 2013a, 2017) y cerámicos (Lema 2015). Si bien estos trabajos aportan datos valiosos, no encontramos antecedentes que problematicen la alimentación con base en el conjunto de datos obtenidos en diferentes líneas analíticas.

Por lo tanto, en este artículo proponemos abordar de forma amplia la materialidad asociada a la alimentación en contextos mineros. Puntualmente, buscamos aportar a su conocimiento en las áreas precordilleranas del noroeste de la provincia de Mendoza, centrándonos en dos casos de estudio que abordamos de forma comparativa: los sitios Minas Paramillos Sur (en adelante MPS), con extracción de plata y oro, y Mina La Atala (desde ahora MLA) (Sironi 2015a, 2018), en la cual se obtenían esquistos bituminosos. Ambos corresponden al periodo que abarca la segunda mitad del siglo XIX y la primera mitad del siglo XX, lapso que de modo heurístico definimos como una unidad de análisis.

Trataremos este problema desde la perspectiva de la antropología de la alimentación, considerando que la preparación y el consumo de alimentos cumplen una función importante en el establecimiento de las relaciones dentro y entre diferentes grupos sociales. Su importancia analítica radica en que alrededor de la comida se normalizan hábitos y prácticas que permiten observar tanto identidades como jerarquías de estatus, clase, género o edad, entre otras (Douglas 1997; Lévi-Strauss 1968). Con respecto a la comprensión de estructuras de clase y estilos de vida, un aspecto interesante es aportado por J. Goody (1995), quien propone integrar al análisis los procesos de producción, distribución, preparación, consumo y eliminación de los alimentos. El ámbito minero se caracterizó por espacios que eran al mismo tiempo domésticos y productivos, y en los que la comida y la bebida tuvieron un papel mediador en la reproducción o en 
el cambio de las relaciones sociales y políticas (Baudrillard 1995; Bulmer 1975; Knapp 1998; Pollock 2015).

A la vez, las prácticas en torno a la alimentación se dieron en asociación a materialidades diversas, lo que permite su análisis arqueológico (Marschoff 2011, 2014). Especialmente, nos interesa analizar cómo mediaron los objetos en la distribución de los alimentos (Mafferra, Sironi y López 2012; Sironi, Mafferra y López 2016), en diferentes escalas. Por ello, proponemos distinguir materialidades que estimamos se incluyeron en circuitos de distribución global, regional o local. Todos estos se asociaron a tipos de consumo diferentes y en esa medida evaluaremos cómo fue su incidencia en los dos casos bajo estudio. Además, nos interesa indagar cómo influyeron los objetos en la distribución de alimentos hacia el interior de los sitios y cómo formaron posiblemente parte del modelo de racionamiento fomentado por las empresas mineras durante el periodo de estudio, el cual hace esperable un dilatado control hacia el proletariado minero, de acuerdo con los antecedentes (Chiavazza 2012; Lallemant 1890; Sironi 2013b).

Planteamos observar también cómo los objetos hallados se relacionan con diferentes fases de la cadena operativa que involucra la alimentación. Buscamos registrar cuáles de estas fases se presentan de forma más frecuente, lo que puede resultar útil para inferir actividades comunes y, con base en ello, caracterizar tipos de ocupación. Para completar la interpretación de las materialidades estudiadas, incluiremos el análisis de documentación histórica que nos permitirá ajustar el marco contextual de las discusiones propuestas.

\section{Propuesta metodológica}

Para comprender la alimentación como fenómeno relacional, proponemos analizar las materialidades y los discursos asociados a los contextos mineros precordilleranos del noroeste de la provincia de Mendoza: MPS y MLA (Sironi 2015a, 2018). En primer lugar, los materiales arqueológicos se diferencian entre objetos del comer y productos alimenticios. Los primeros incluyen a todos aquellos relacionados con la alimentación, ya sean utensilios, contenedores o procesadores, entre otros. Los diversos materiales fueron primero estudiados como generalmente se acostumbra en la arqueología, en razón de su tecnotipología. Este análisis siguió criterios formales asociados al tipo de material y tecnología de producción; tratamientos de superficie; marcas, sellos o decoración; forma; defectos de manufactura; huellas de uso y evidencias de procesos posdepositacionales. 
Especialmente, observamos criterios de análisis propuestos para materiales cerámicos (Schávelzon 2000), restos de vidrio (Sironi 2013a) y objetos de metal (Quiroga 2005). En segundo lugar, con respecto a los productos alimenticios, nos referimos a los restos de materias primas o alimentos elaborados consumidos durante la ocupación. En este caso, son exclusivamente restos óseos de fauna y restos vegetales asociados a semillas o frutos (carporrestos). Buscamos identificar taxonómicamente los materiales y registrar marcas antrópicas asociadas a las actividades de procesamiento, consumo y descarte. Para el caso de los restos óseos de fauna, seguimos los criterios de Mengoni (2010), y para los carporrestos, los de Buxó (1997) y Sironi (2016).

En particular, proponemos analizar las materialidades en razón de algunas categorías que sirven para comparar aspectos asociados a la alimentación entre los sitios de estudio. Basaremos nuestra propuesta en la diferenciación de los objetos por su forma y función; la forma está asociada a un conjunto de características que permiten distinguir un objeto en una tipología y determinar su función, bien sea su uso o utilidad. Con base en dicha distinción, evaluamos de modo heurístico algunos aspectos que serán relevantes para la consecución de nuestros objetivos. En este sentido, procuraremos referenciar los objetos recuperados en relación con escalas espaciales y temporales.

En primer lugar, buscaremos relacionar los restos hallados con circuitos de distribución, que delimitamos como intrasitio, regional y global, e identificamos a partir de ciertas características materiales de los objetos o productos asociados a estos. En el caso de la escala global, la relacionamos con productos que son transportados continental o intercontinentalmente. Aquí integramos objetos con características físicas que permiten su transporte a grandes distancias, ya sean lo suficientemente resistentes para su acopio y transporte masivo (como las latas de conserva), o bien objetos más frágiles que circulan de modo más restringido con alimentos o bebidas de carácter suntuario (como recipientes de vidrio que contienen destilados o vinos). Por otro lado, la escala de distribución regional se encuentra asociada a objetos y mercancías alimentarias que se intercambian intrarregionalmente. En esta se integran objetos que resisten un traslado amplio, no tan extenso como en la escala global, pero sí a una escala nacional o entre países limítrofes. Lo mismo ocurre con el tipo de objetos más frágiles y con menor capacidad de conservación en el tiempo de los alimentos que contienen o bien productos más perecederos o de inferior valor. Entre estos podemos encontrar los barriles, damajuanas o frascos de conserva ${ }^{1}$. En esta

1 La damajuana o garrafa es un recipiente utilizado para conservar vinos o aceites. Su capacidad es de entre 4 y 10 litros, y es en general de vidrio; para darle resistencia y estabilidad, es 
categoría se incluye también el ganado vacuno que podía ser trasladado a pie a grandes distancias. Una última escala de distribución es la del sitio, en la que se cuentan todos los objetos producidos en el lugar o que servían para la distribución de los alimentos entre las personas que formaban parte de la ocupación. Entre los primeros podemos nombrar los animales que se criaban o cazaban en el lugar y entre los segundos, todos aquellos objetos relacionados con el servicio o consumo de los alimentos.

En segundo lugar, procuramos asociar los mismos materiales a diferentes fases de la cadena de operaciones implicadas en la alimentación (Goody 1995; Lemonnier 1986). Con el fin de evitar confusiones, para estas categorías observamos solo los objetos del comer, sin contemplar los productos alimenticios. Diferenciamos las fases de obtención/producción, distribución, preparación y consumo (Goody 1995). También distinguimos objetos utilizados para la obtención, como los asociados a la recolección o producción directa de materias primas comestibles y a la distribución, en particular, refiriéndonos a aquellos que sirven para contenerlas durante su traslado desde un lugar de producción hasta uno de consumo. Además, identificamos objetos que sirvieron al acopio de alimentos en el sitio, es decir, al resguardo para su uso diferido en el tiempo. Por último, diferenciamos elementos que participaron en la cocción o transformación final de los alimentos y los asociados a su consumo.

Analizar en conjunto materiales arqueológicos diversos, que son además un registro esencialmente fragmentario, limita las posibilidades de diferenciar de forma cuantitativa las asociaciones relacionadas con las categorías descritas. Por lo mismo, solo compararemos la cantidad de tipos de objeto (diferenciados por su forma y función) presente por categorías. Nuestros objetivos podrán discutirse además en función del análisis de información documental, específicamente, diarios y relatos de viajeros (Haigh [1831] 1920; Vicuña 1856), artículos periodísticos ("La minería” 1921), informes oficiales (Bialet 1904; Lallemant 1890; Segundo Censo de la República Argentina 1895), así como expedientes de la Dirección General de Minería de la provincia de Mendoza, para MPS (ADMPM, expediente 748-T-1939) y para MLA (ADMPM, expediente 928-S-1917). Este tipo de información permite precisar aspectos generales relativos a las características y funcionalidad de los sitios, así como caracterizar los diversos actores sociales que intervinieron en ellos. Lo anterior posibilita, además, apuntalar algunos aspectos relacionados con nuestros objetivos que son complejos de resolver desde la materialidad, tales como identificar asimetrías sociales hacia dentro de la

recubierto de mimbre $u$ otro material. Los frascos son recipientes cilíndricos de vidrio de diverso tamaño $\left(300-5.000 \mathrm{~cm}^{3}\right)$ y se utilizan para conservar alimentos. 
ocupación, así como comprender mejor la manera en que se incorporaron algunos productos o se definieron tipos de consumo.

\section{Área de estudio: Minas Paramillos Sur y Mina La Atala}

Los sitios históricos arqueológicos denominados MPS y MLA se localizan en el ambiente precordillerano, caracterizado por abruptas quebradas transversales que conectan la precordillera con el piedemonte y la llanura (figura 1), sin cursos de agua permanente, aunque salpicadas de pequeños manantiales o vertientes. En este paisaje, el recurso hídrico coincide con los sectores deprimidos de quebradas, por lo que tales rasgos del terreno (quebradas en un relieve irregular y agua en un ambiente árido) son considerados claves debido a la disponibilidad hídrica para la estructuración y mantenimiento de los asentamientos. En el sector de puna, la hidrografía es muy pobre en aguas permanentes y rica en cárcavas, torrenteras y uadis (ríos secos o estacionales) que se activan en verano, al dirigirse hacia las partes bajas y formar numerosos conos aluviales. El recurso hídrico en el sector del piedemonte se presenta en líneas de aguadas (activas o secas) que posibilitan el asentamiento y la localización de emplazamientos de puestos ganaderos y, en nuestro caso, mineros (Abraham 2000; Prieto 2007).

Dentro de la microrregión Paramillos de Uspallata, sector históricamente aprovechado para la extracción de oro, plata y cobre (Cueto 2003; Juan 2004; Santos 1961; Sironi 2013b), se ubica el sitio denominado MPS — georreferencia: $32^{\circ} 30^{\prime} 36,64^{\prime \prime} \mathrm{S} 69^{\circ} 05^{\prime} 35,71^{\prime \prime} \mathrm{W}$ y a una altitud aproximada de $3.065 \mathrm{~m}$ s. n. m.(ADMPM, expediente 748-T-1939). Este sitio comprende 18 estructuras arquitectónicas con diversas funcionalidades y asociadas a 109 piques y socavones correspondientes a la segunda mitad del siglo XIX y comienzos del XX, los cuales se distribuyen en un radio de $1,5 \mathrm{~km}^{2}$ (figura 2). Dichas instalaciones domésticoproductivas y labores mineras se encuentran interconectadas por 17 sendas y caminos que permiten la circulación de personas, máquinas y transportes vinculados a la producción minera (Sironi 2015a, 2015b).

En la cuenca aluvional denominada Divisadero Largo, dentro de la reserva natural homónima del ecosistema de piedemonte (Abraham 2000), en un área comprendida entre los $32^{\circ} 52^{\prime} 22^{\prime \prime}$ y $32^{\circ} 52^{\prime} 46^{\prime \prime} \mathrm{S}$ y los $68^{\circ} 56^{\prime} 12^{\prime \prime}$ y $68^{\circ} 55^{\prime} 28^{\prime \prime} \mathrm{W}$, aproximadamente (ADMPM, expediente 928-S-1917), se realizaron las labores arqueológicas del sitio MLA (Sironi 2018). Este se caracterizó por concentrar las 
Figura 1. Ubicación de las Minas Paramillos Sur y Mina La Atala

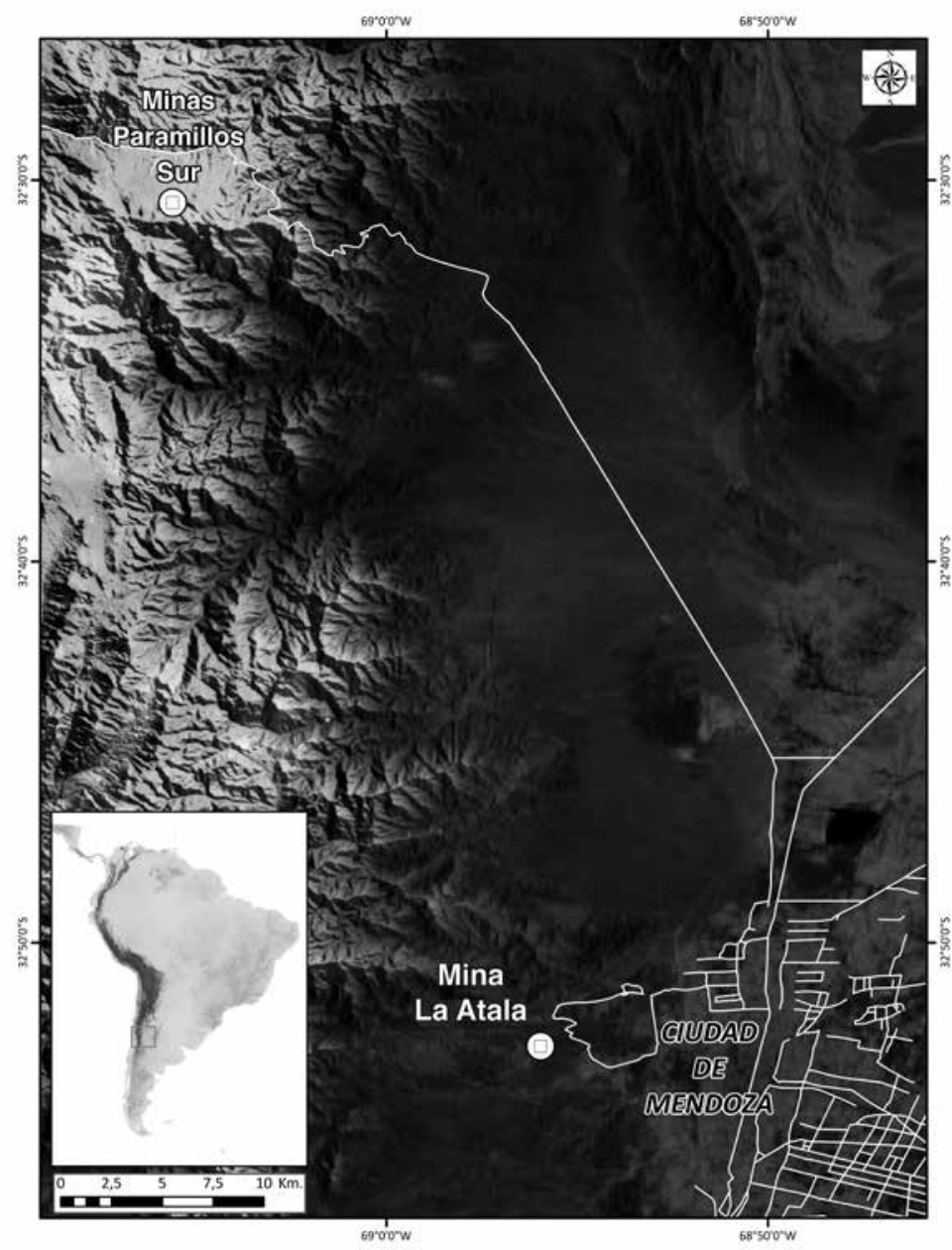

Fuente: tomado de Sironi $(2019,155)$.

explotaciones de esquistos bituminosos para producir el gas del alumbrado público de la ciudad de Mendoza hacia 1889 ("La minería" 1921) y luego iniciar la producción del cemento puzolánico hacia mediados del siglo XX. Este sitio (figura 3), de menor envergadura que MPS, está constituido por dos socavones, cuatro canteras a cielo abierto y tres conjuntos arquitectónicos que suman un total de diez estructuras claramente diferenciadas por funciones domésticas y productivas (Sironi 2015b). 
Figura 2. Vista del núcleo habitacional del complejo minero Minas Paramillos Sur

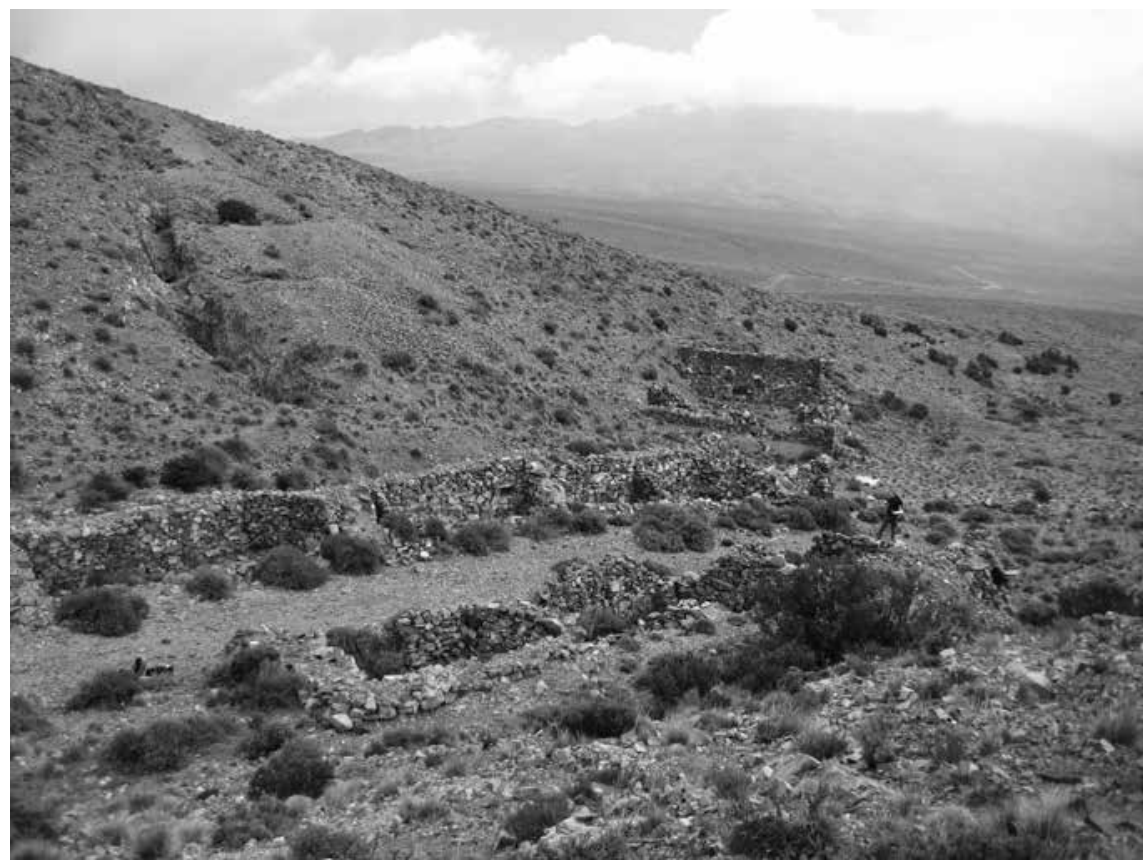

Fuente: fotografía tomada por Osvaldo Sironi en el 2012.

Figura 3. Vista del núcleo administrativo del complejo minero Mina La Atala

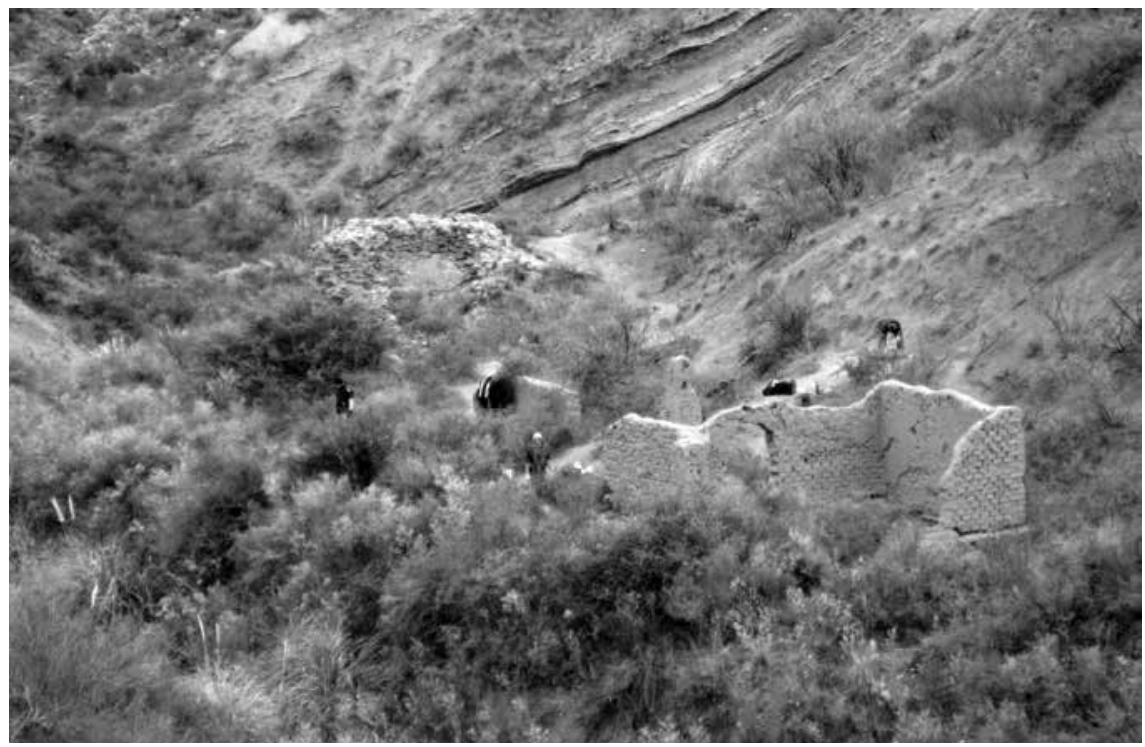

Fuente: fotografía tomada por Osvaldo Sironi en el 2013. 
Los métodos de trabajo de campo incluyeron prospecciones intensivas pedestres para delimitar y diferenciar las áreas domésticas y las de producción de minerales. Asimismo, se realizó un estudio topográfico de dichas áreas y se aplicaron recolecciones superficiales y excavaciones dentro y fuera de los recintos arquitectónicos detectados, lo que nos permitió evaluar los periodos y procesos de ocupación de ambos sitios. A partir de los distintos hallazgos arqueológicos, se configuró un esquema cronoestratigráfico correspondiente a lapsos históricos de MPS y MLA con diferentes escalas de tiempo, que es producto de la relación estratigráfica y profundidades (promediadas y generalizadas para todas las excavaciones) de los emplazamientos mineros mencionados, que permitieron establecer criterios de relativa sincronía (tabla 1). Las áreas excavadas no presentaron indicios de procesos posdepositacionales que posibiliten inferir alteraciones en la conservación y formación de los registros arqueológicos.

En MPS las ocupaciones se atribuyen a tres fases. La primera es del periodo republicano (entre fines del siglo XIX y la primera década del XX). Esta fase se encuentra representada por materiales cerámicos (vidriadas tipo carrascal) y restos de vidrio de botellas de ginebra cuadradas, además de clavos y otros elementos metálicos, como cartuchos de bala y piezas de herramientas manuales. La segunda corresponde a la primera mitad del siglo XX. En este caso se halló un zapato femenino, al que se suman abundantes restos de vidrio y metálicos. Menos abundantes, pero muy variables y fragmentadas, son las losas whiteware ${ }^{2}$ correspondientes a este periodo. En la tercera fase, se incluyen elementos subactuales, como fragmentos vítreos y metálicos (Sironi 2015b, 2018).

En el caso de MLA las ocupaciones iniciales se atribuyen a fines del siglo XIX (por lo menos desde 1890), representadas por escasos restos de vidrio de botellas de vino jerez. La segunda fase corresponde a la primera mitad del siglo $\mathrm{XX}$, evidenciada por abundantes restos de vidrio y elementos metálicos, escasas lozas whiteware y un zapato masculino. La tercera fase corresponde, al igual que MPS, a elementos subactuales, como vidrios y metales (Sironi 2016, 2018). 
Tabla 1. Esquema cronoestratigráfico relativo basado en contextos y tipologías de materiales (vidrios, metales y lozas) definidos para MPS y MLA

\begin{tabular}{l|c|c|c|c}
\multirow{4}{*}{ Sitio } & $\begin{array}{c}\text { Nivel } \\
\text { estratigráfico }\end{array}$ & $\begin{array}{c}\text { Profundidades } \\
(\mathbf{c m})\end{array}$ & $\begin{array}{c}\text { Datación } \\
\text { relativa }\end{array}$ & $\begin{array}{c}\text { Densidad de } \\
\text { materiales por } \\
\text { nivel }\left(\mathbf{N} / \mathbf{m}^{3}\right)\end{array}$ \\
\cline { 2 - 4 } $\begin{array}{l}\text { Minas Paramillos } \\
\text { Sur }\end{array}$ & Nivel 1 & $0-20$ & $1950-1970$ & \multirow{2}{*}{540,57} \\
\cline { 2 - 4 } & Nivel 2 & $20-60$ & $1910-1950$ & \\
\cline { 2 - 4 } \multirow{3}{*}{$\begin{array}{l}\text { Mina } \\
\text { La Atala }\end{array}$} & Nivel 3 & $60-100$ & $1870-1910$ & \multirow{2}{*}{240,5} \\
\cline { 2 - 4 } & Nivel 1 & $0-35$ & $1940-1970$ & \\
\cline { 2 - 4 } & Nivel 2 & $35-70$ & $1910-1940$ & \\
\hline
\end{tabular}

Fuente: tomado de Sironi (2015b).

\section{Resultados del análisis histórico-arqueológico}

\section{Registro cerámico}

De las recolecciones superficiales y las excavaciones de los sitios MPS y MLA se recuperó un total de 2.421 tiestos cerámicos de manufactura histórica, los cuales comparten características con los estudiados en diversos sitios de la ciudad de Mendoza (Puebla, Zorrilla y Chiavazza 2005). Los grupos cerámicos presentes en estos contextos son las cerámicas rojas, lozas, porcelanas y cerámicas vidriadas (tabla 2).

Tabla 2. Data de la distribución espacial de materiales cerámicos en MPS y MLA

\begin{tabular}{l|c|c|c|c}
\hline $\begin{array}{c}\text { Data distribucional del registro } \\
\text { cerámico }\end{array}$ & MPS & MLA & N & $\begin{array}{c}\text { Porcentaje } \\
(\%)\end{array}$ \\
\hline Cerámica roja & 2.303 & - & 2.303 & 98,38 \\
\hline Cerámica vidriada & 6 & - & 6 & 0,26 \\
\hline Loza & 22 & 12 & 34 & 1,45 \\
\hline Porcelana & 10 & - & 10 & 0,43 \\
\hline Total & 2.341 & 12 & 2.353 & 100 \\
\hline
\end{tabular}

Fuente: tomado de Sironi (2015b). 
El material cerámico de MLA se encuentra localizado puntualmente en el sector doméstico-habitacional, en donde se presenta de modo superficial $(\mathrm{N}=10)$ y a los $40 \mathrm{~cm}$ de profundidad ( $\mathrm{N}=2$ ) (Sironi 2018). La totalidad de los fragmentos cerámicos hallados son lozas clasificadas tipológicamente como whiteware, que corresponden a platos, de los cuales ensamblan cuatro fragmentos y una taza. Dichos elementos se identificaron a partir del hallazgo de fragmentos de cuerpo $(0,21 \%)$, base $(0,17 \%)$, borde $(0,09 \%)$ y asa $(0,04 \%)$.

En el caso de MPS, los tiestos cerámicos fueron hallados mayoritariamente en sectores públicos - patio interno y área de descarte-. Sironi (2015a) sostiene que el control del agua para su ingesta se establecía en los sectores administrativo-habitacionales, ya que los 2.303 fragmentos de tinaja (correspondientes a un mismo recipiente) estaban dispersos en su gran mayoría entre los 0 y $15 \mathrm{~cm}$ de profundidad del denominado patio interno. El material cerámico descartado se adscribe a principios y mediados del siglo XX, cronologías que evidencian que las actividades de desecho fueron contemporáneas al uso del emplazamiento.

La reconstrucción por remontaje o ensamblaje de formas completas no fue posible, dada la elevada fragmentariedad del registro. Con base en el estudio de piezas enteras ha sido posible la reconstrucción hipotética de formas, a partir de fragmentos diagnósticos — sobre todo en lozas y vidriados-, que pudieron ser remontados y ensamblados parcialmente. La proporción de partes diagnósticas que permitieron identificar artefactos en MPS es muy baja (4,59\%). Se puede percibir que la proporción de fragmentos de cuerpos (12,07\%), indeterminados (4,84\%) y esquirlas (78,5\%) supera ampliamente la de partes diagnósticas (tabla 3). En nuestro caso, se consideran partes diagnósticas fragmentos que pertenecen a bordes, bases, asas y cuellos de piezas. Los fragmentos de cuerpo, indeterminados ${ }^{3}$ y esquirlas ${ }^{4}$, en cambio, no son diagnósticos para definir esas variables. Esto dificulta el cálculo del número mínimo de piezas y la inferencia acerca de su identificación artefactual.

3 Los fragmentos indeterminados no pueden adjudicarse a partes de la pieza.

4 Las esquirlas son elementos que no tienen superficie y son menores a 0,5 cm de diámetro. 
Tabla 3. Data distribucional de fragmentos diagnósticos y no diagnósticos según la tipología cerámica

\begin{tabular}{l|c|c|c|c|c|c|c|c}
\hline Tipología & \multicolumn{3}{|c|}{$\begin{array}{c}\text { Fragmentos } \\
\text { diagnósticos }\end{array}$} & \multicolumn{3}{c|}{$\begin{array}{c}\text { Fragmentos } \\
\text { no diagnósticos }\end{array}$} & N & $\begin{array}{c}\text { Porcentaje } \\
(\%)\end{array}$ \\
\cline { 1 - 9 } & Borde & Base & Asa & Cuerpo & Esquirla & Indeterminado & & \\
\hline $\begin{array}{l}\text { Cerámica } \\
\text { roja }\end{array}$ & 8 & 72 & - & 262 & 1.847 & 114 & 2.303 & 97,88 \\
\hline $\begin{array}{l}\text { Cerámica } \\
\text { vidriada }\end{array}$ & 1 & 3 & - & 2 & - & - & 6 & 0,25 \\
\hline Loza & 6 & 10 & 1 & 17 & - & - & 34 & 1,45 \\
\hline Porcelana & 6 & 1 & - & 3 & - & - & 10 & 0,42 \\
\hline Total & 21 & 86 & 1 & 284 & 1.847 & 114 & 2.353 & 100 \\
\hline
\end{tabular}

Fuente: tomado de Sironi (2015b).

De acuerdo con el estudio específico de fragmentos diagnósticos se ha podido calcular un número mínimo de piezas enteras (figura 4), de las cuales solo la tipología loza se presenta en ambos sitios:

a. Cerámica roja: a partir de las bases y bordes se determinó la cantidad de una tinaja y un cuenco (único fragmento de cuerpo).

b. Loza: en este tipo de material, la proporción de partes diagnósticas y no diagnósticas ( $\mathrm{N}=34$ ) fue exactamente equitativa, ya que se distribuyen en un $50 \%$ para cada una. Una taza, un cuenco y dos platos (a partir de las características que presentan los bordes), y dos platos (según el número mínimo de bases).

c. Porcelana: a partir de la existencia de pequeños fragmentos de bordes, base y cuerpos (porcelana europea), inferimos la presencia de tres piezas como mínimo. Se contabilizaron dos piezas de vajilla de porcelana (tazas) y un plato.

d. Cerámica vidriada: en este caso, se hizo el cálculo del número mínimo de piezas a partir de los bordes y bases. El total de piezas ascendió a dos, representadas por un cuenco y un lebrillo.

Como puede observarse en los resultados presentados, se evidencia un predominio de la cerámica local (en este caso se vincula al almacenamiento de agua, recurso que es crítico en estos paisajes) y la loza (lo que confirma el alcance logrado con la industrialización y exportación de este producto). 
Figura 4. Tiestos correspondientes a cerámica roja (tinaja), lozas y porcelanas correspondientes a MPS y MLA

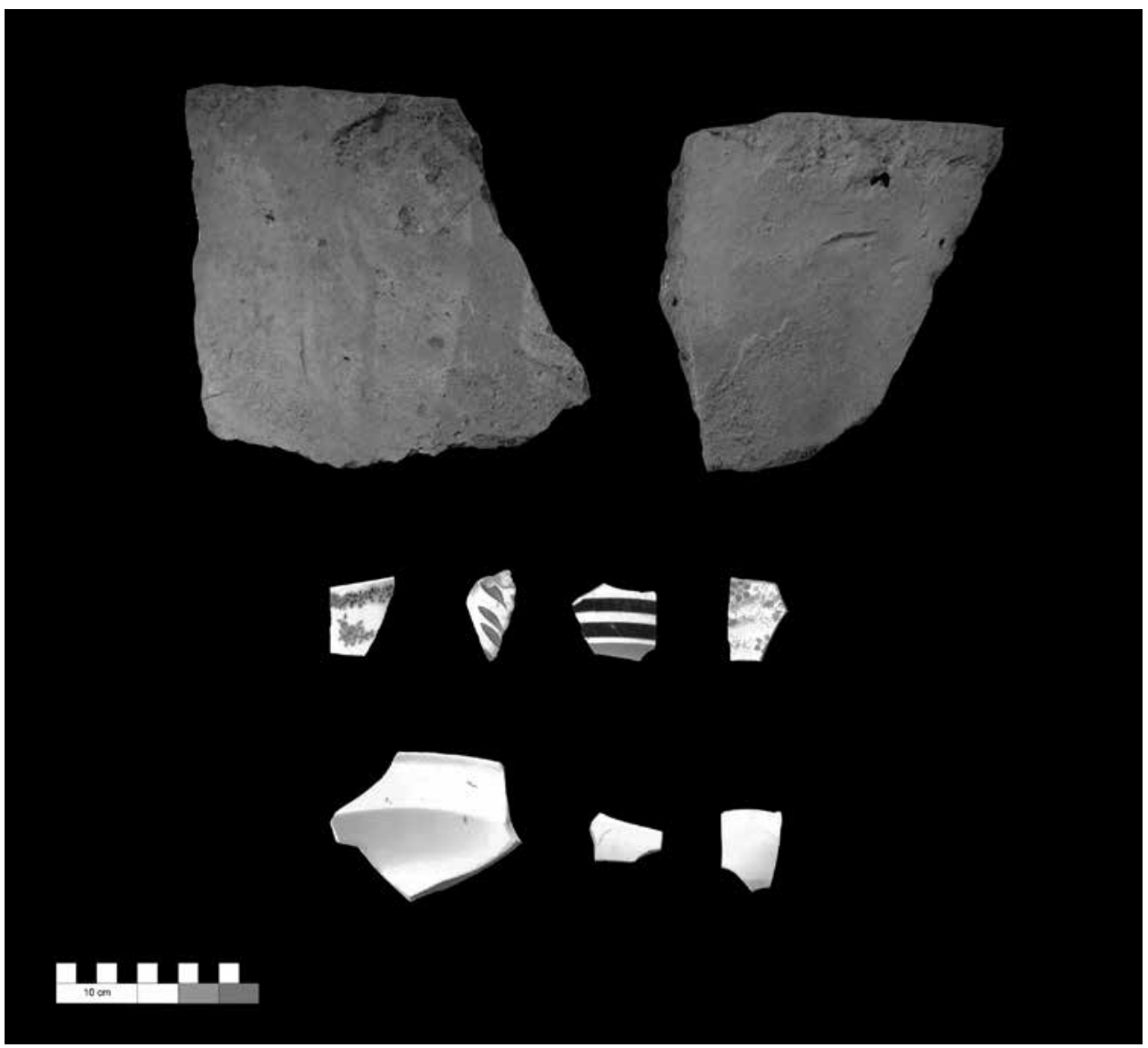

Fuente: tomado de Sironi (2015b).

\section{Registro vítreo}

De todos los elementos vítreos vinculados a prácticas alimentarias, se contabilizó un total de 527 fragmentos (tabla 4), entre los cuales se pudieron reconstruir y tomar como diagnósticos solo 51 elementos, es decir el 9,68\% del total. Las tipologías de los fragmentos vítreos identificados se distribuyen en botellas $(\mathrm{N}=289)$, frascos de conservas $(\mathrm{N}=26)$, damajuanas $(\mathrm{N}=169)$, jarras $(\mathrm{N}=3)$, vasos $(\mathrm{N}=7)$, tazas $(\mathrm{N}=21)$ y platos $(\mathrm{N}=12)$. A modo de aclaración, en la tipología general de botellas se encuentran los materiales clasificados como bebidas alcohólicas (vino, ginebra y cerveza) y sin alcohol (gaseosa y agua). 
Tabla 4. Fragmentos diagnósticos y no diagnósticos según la forma en función vítrea en MPS y MLA

\begin{tabular}{|c|c|c|c|c|c|c|c|c|}
\hline Tipología & \multicolumn{3}{|c|}{ MPS } & \multicolumn{3}{|c|}{ MLA } & \multirow[t]{2}{*}{ N } & \multirow{2}{*}{$\begin{array}{c}\text { Porcentaje } \\
(\%)\end{array}$} \\
\hline Vítrea & Borde/pico & Base & Cuerpo & Borde/pico & Base & Cuerpo & & \\
\hline Botella & 33 & 14 & 134 & 7 & 5 & 96 & 289 & 54,84 \\
\hline $\begin{array}{l}\text { Frasco de } \\
\text { conserva }\end{array}$ & - & - & 12 & 1 & 3 & 10 & 26 & 4,93 \\
\hline Damajuana & 1 & - & 46 & 7 & 12 & 103 & 169 & 32,07 \\
\hline Jarra & 1 & - & 2 & - & - & - & 3 & 0,57 \\
\hline Vaso & - & - & 5 & - & - & 2 & 7 & 1,33 \\
\hline Taza & - & - & 21 & - & - & - & 21 & 3,98 \\
\hline Plato & 1 & - & 11 & - & - & - & 12 & 2,28 \\
\hline Total & 36 & 14 & 231 & 15 & 20 & 211 & 527 & 100 \\
\hline
\end{tabular}

Fuente: tomado de Sironi (2015b).

La totalidad de estos objetos se integra en una clasificación general, según funciones específicas dentro de la secuencia operacional en las prácticas alimentarias, es decir, cuáles son los tipos de elementos que se presentan en los contextos mineros que hacen referencia a la distribución y al consumo de alimentos. De esta manera, se incluyen en funciones de distribución (92,03\%) los 485 fragmentos de botellas, damajuanas y frascos de conserva. En menor porcentaje se presentan los usos de consumo (7,97\%) conformados por fragmentos de jarra, vaso, taza y plato $(\mathrm{N}=42)$.

Los elementos representativos tipológicos de artefactos $(\mathrm{N}=51)$ que se pudieron remontar o ensamblar para hacer una identificación específica fueron: botellas de gaseosa $(\mathrm{N}=2)$, frascos de conserva $(\mathrm{N}=7)$, botellas de vino $(\mathrm{N}=16)$, botellas de agua $(\mathrm{N}=3)$, botellas de jerezana $(\mathrm{N}=2)$ botellas de ginebra $(\mathrm{N}=6)$, botellas de cerveza $(\mathrm{N}=2)$, damajuana $(\mathrm{N}=8)$, jarra $(\mathrm{N}=3)$ y vaso $(\mathrm{N}=2)$.

A los estudios tipológicos presentados es necesario incorporar el análisis de las marcas de fabricación que aparecen en los elementos diagnósticos, ya que a partir de ellas se puede determinar el tipo de manufactura con que se elaboraron los objetos de vidrio y tener un referente temporal de fabricación. De estos elementos diagnósticos se reconoció que los recipientes y artefactos de moldes mecánicos o semiautomáticos (aquellos que son soplados en moldes o elaborados por moldes) son el 76,47\% y los de fabricación automática o de inyección industrial, el 23,53\% (figura 5). Al relacionar las marcas de fabricación con los periodos en los que se pueden ubicar, se aprecia que los objetos de fines del siglo XIX y principios 
del XX son el 69,57\%, mientras que los de mediados del siglo XIX representan el $2,17 \%$, y los elementos diagnósticos del siglo XX son el $28,26 \%$ del total.

Figura 5. Arriba: picos de botellas de vino, licor y damajuana. Abajo: bases de botella de vino, jerez y ginebra. Todos correspondientes a 1870-1880 y 1920-1930
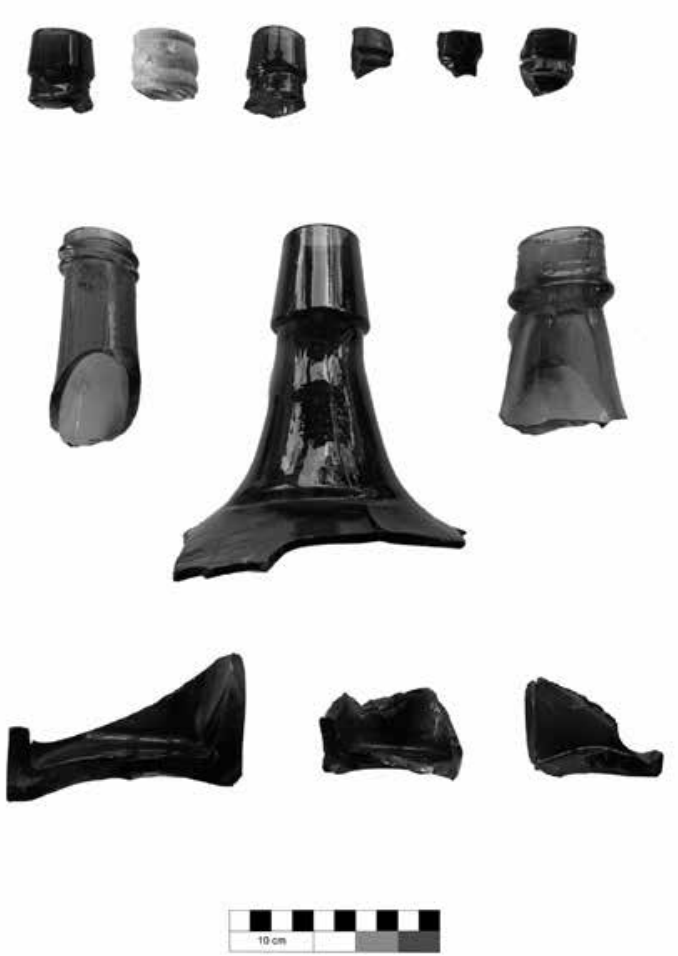

Fuente: tomado de Sironi (2015b).

\section{Registro metálico}

A continuación presentamos el resultado del análisis de los materiales arqueológicos metálicos recuperados en los emplazamientos mineros MPS y MLA, que ascienden a un total de 246 elementos (tabla 5, figura 6). Estos se distribuyen en hierro $(\mathrm{N}=92,68)$, bronce $(\mathrm{N}=6,5)$ y plomo $(\mathrm{N}=0,81)$. Una primera catalogación analítica consistió en identificar los artefactos correspondientes a utensilios de cocina y recipientes de alimentos envasados. Otro de los subgrupos tipológicos que hemos tenido en cuenta son los elementos correspondientes a armas de fuego, ya que podrían sugerir prácticas de caza de fauna autóctona. 
Tabla 5. Objetos metálicos vinculados a prácticas de alimentación: MPS y MLA

\begin{tabular}{|c|c|c|c|c|}
\hline \multicolumn{2}{|c|}{ Objeto } & MPS & MLA & Porcentaje (\%) \\
\hline \multirow{2}{*}{ Utensilios de cocina } & Pava & 1 & & 0,41 \\
\hline & Cuchara & 1 & & 0,41 \\
\hline \multirow{4}{*}{ Alimentos envasados } & Fleje barril & 6 & 1 & 2,85 \\
\hline & Recipiente & \multirow{2}{*}{172} & \multirow{2}{*}{44} & \multirow{2}{*}{87,79} \\
\hline & Latas de conserva & & & \\
\hline & Tapas de botella & - & 4 & 1,62 \\
\hline \multirow{3}{*}{ Armas de fuego } & Vaina & 5 & 4 & 3,66 \\
\hline & Fulminante & 6 & - & 2,44 \\
\hline & Bala impactada & 2 & - & 0,82 \\
\hline \multicolumn{2}{|l|}{ Total } & 193 & 53 & 100 \\
\hline
\end{tabular}

Fuente: tomado de Sironi (2015b).

Figura 6. Elementos metálicos vinculados a alimentos de conservas (carne enlatada, sopa, atún), vainas balísticas (evidencia de caza de fauna) y fragmento de cuchara (utensilio de cocina)
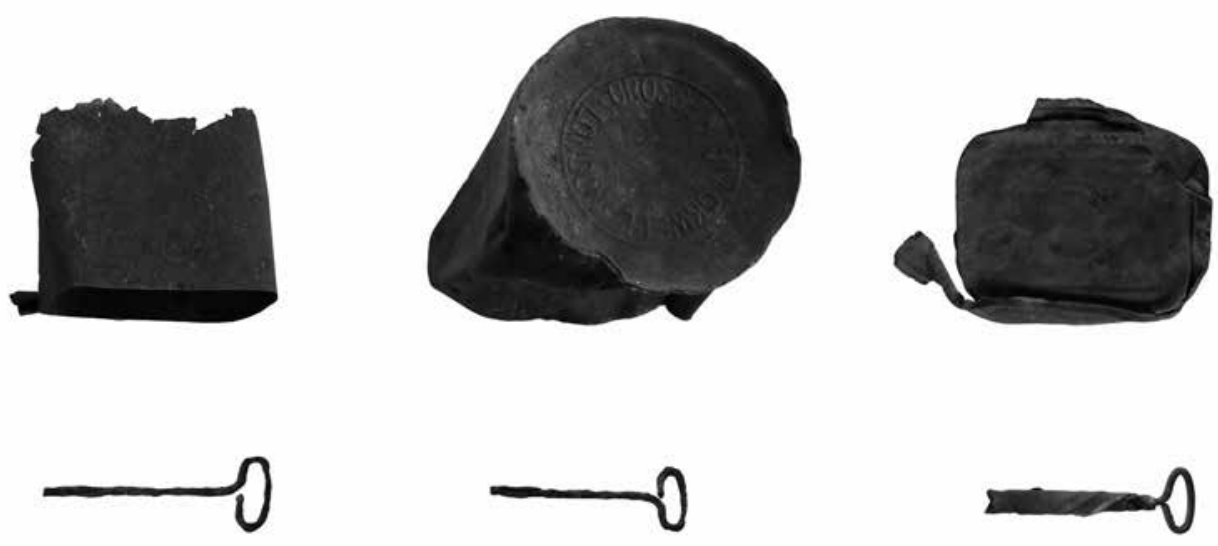

\section{$\because 11$}

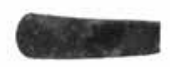

Fuente: tomado de Sironi (2015b). 


\section{Registro de origen animal y vegetal}

Se hallaron 316 elementos arqueofaunísticos, de los cuales 103 pudieron ser reconocidos (32,59\%), 25 resultaron irreconocibles (7,91\%) respecto a orden y especie, mientras que 188 fueron considerados astillas. La gran cantidad de estas $(59,49 \%$ de la muestra) sugiere un alto grado de fraccionamiento de las presas o animales consumidos, acción que posiblemente estuvo orientada a optimizar al máximo el aprovechamiento cárnico. Si bien los elementos indeterminados no pudieron ser asignados a un género o especie, sí fueron reconocidos —en su mayoría- como elemento anatómico determinado. En la tabla 6 se pueden observar los diferentes taxones identificados y su respectiva proporción dentro del registro. Cabe mencionar que en la muestra no se han podido determinar huesos de microrroedores ni reptiles, aunque su representación pudo ser identificada en las huellas detectadas en los registros.

Tabla 6. Abundancia taxonómica en MPS y MLA: NISP

\begin{tabular}{l|c|c|c} 
Identificación taxonómica & MPS & MLA & $\begin{array}{c}\text { Porcentaje } \\
(\%) \text { NISP }\end{array}$ \\
Ave ind. & 1 & - & 0,78 \\
\hline Guanaco: Lama guanicoe & 55 & - & 42,97 \\
\hline Vaca: Bos taurus & 33 & 8 & 32,03 \\
\hline Chivo: Capra hircus & 7 & - & 5,47 \\
\hline Mammalia ind. & 21 & 3 & 18,75 \\
\hline Total & 117 & 11 & 100 \\
\hline
\end{tabular}

Fuente: tomado de Sironi (2015b).

En cuanto al análisis de consumo de recursos faunísticos, se consideraron los especímenes de los taxones Lama guanicoe (guanaco) y Bos taurus (vaca), ya que representan los recursos más abundantes del registro arqueozoológico (con un $75 \%$ NISP) y los que presentan marcas de procesamiento y consumo. Considerando la división entre el esqueleto axial y apendicular, los resultados obtenidos del MNE, el MAU y el porcentaje MAU (Sironi et al. 2013) indicaron que las partes esqueletales predominantes de Lama guanicoe y Bos taurus son las pertenecientes al esqueleto apendicular (tabla 7, figura 7). Se puede observar que este último representa un 56,35\% del MNE de ambos taxones. Con respecto al esqueleto axial $(43,65 \%)$, este se encuentra principalmente representado por una alta proporción de costillas y vértebras de ambos taxones (90,74\%). 
Tabla 7. Modificaciones superficiales óseas y porciones esqueletarias presentes en los taxones Lama guanicoe y Bos taurus de MPS y MLA

\begin{tabular}{|c|c|c|c|c|}
\hline \multirow{3}{*}{ Marcas antrópicas } & \multirow{2}{*}{\multicolumn{2}{|c|}{ Lama guanicoe }} & \multicolumn{2}{|c|}{ Bos taurus } \\
\hline & & & \multicolumn{2}{|c|}{ (NISP: 41) } \\
\hline & N & $\begin{array}{c}\text { Porcentaje } \\
(\%)\end{array}$ & N & $\begin{array}{c}\text { Porcentaje } \\
\text { (\%) }\end{array}$ \\
\hline Corte de cuchillo & 7 & 12,73 & 8 & 19,51 \\
\hline Corte de sierra manual & 1 & 1,82 & 2 & 4,88 \\
\hline Corte de sierra mecánica & 5 & 9,09 & 6 & 14,63 \\
\hline \multicolumn{5}{|l|}{ Porciones esqueletarias } \\
\hline Axial & 23 & 41,81 & 19 & 46,34 \\
\hline Apendicular & 32 & 58,19 & 22 & 53,66 \\
\hline
\end{tabular}

La naturaleza cuantitativa del registro arqueobotánico no nos permitió realizar cálculos para establecer inferencias consistentes, ya que la suma total de ambos sitios es baja. No obstante, se considera que la descripción de los atributos y la cuantificación (como indicador de presencia de dicho registro) permite la interpretación de ciertas pautas de descarte y la baja presencia de ciertos registros arqueológicos. Los restos arqueobotánicos hallados en MPS ( $N=18)$ y MLA $(\mathrm{N}=4)$ ascienden a un total de 22 elementos reconocibles, distribuidos en superficie $(\mathrm{N}=4)$ y estratigráficamente $(\mathrm{N}=18)$. Estos fueron detectados en áreas de descarte $(\mathrm{N}=15)$ y en contextos habitacionales $(\mathrm{N}=7)$. De los restos reconocibles se destaca la presencia de durazno (Prunus persica) $(\mathrm{N}=16)$, nuez (Juglans regia) $(\mathrm{N}=5)$ y vid (Vitis sp.) $(\mathrm{N}=1)$. Asimismo, cabe destacar que de todos los carporrestos solo tres elementos presentan termoalteración y su estado fragmentario es: enteros $(\mathrm{N}=5)$, fragmentados —elemento que presenta más del $50 \%$ del resto botánico- $(\mathrm{N}=4)$ y fragmentos $(\mathrm{N}=13)$. 
Figura 7. Arriba: elementos de Lama guanicoe y Bos taurus con marcas antrópicas (huellas de sierra manual y mecánica) y naturales (huellas de raíces y carnívoros). Abajo: restos arqueobotánicos (Juglans regia, Prunus persica y Vitis sp.)

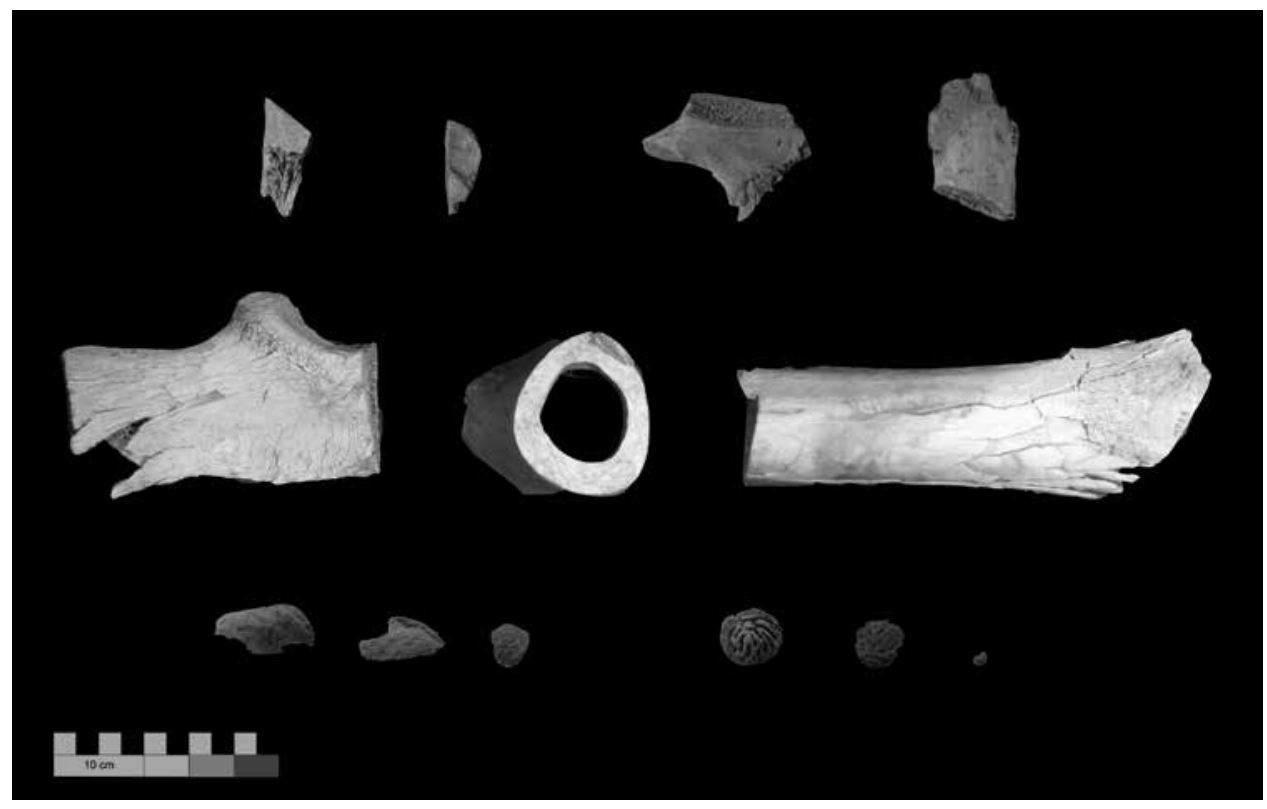

Fuente: tomado de Sironi (2015b).

\section{Registro documental}

El material documental ofrece datos valiosos para comprender las asimetrías sociales en nuestro contexto de estudio. Bialet, en su informe de 1904, presenta una interesante descripción de las condiciones de vida y precarización sociolaboral de las masas proletarias de Mendoza. Esta mirada nos permitirá contar con una referencia sobre las asimetrías sociales existentes hacia adentro de la ocupación de los asentamientos mineros estudiados aquí. Respecto a la clase dirigente de Mendoza (y su contraparte en las clases trabajadoras), describe cómo esta "se mantiene tan separada del pueblo en el siglo XX como en tiempo de la colonia, y corren paralelas sin fundirse como entonces" (Bialet 1904, 154). También observa que

[...] la policía es ineficaz para corregir el juego, la bebida y la ociosidad, que son los únicos placeres que le quedan al pobre; el ahorro es idea que no está en la mente del obrero local; y así se ve que mientras el italiano y el europeo en general se labran rápidamente un bienestar relativo, y muchos se enriquecen, el criollo permanece estacionario en su vida pobre y á veces miserable. (Bialet 1904, 154) 
El autor señala además que la condición sociolaboral del proletariado mendocino es "estacionaria, y esto aun en los extranjeros mismos [...] No hay más idea de la cuestión social que la de pagar el menor jornal y hacer trabajar al obrero lo más que se pueda” (154-155). El médico catalán continúa su informe resumiendo que estas condiciones de vida generan diversas conductas que llevan a "la inmoralidad de las clases obreras. La lujuria, el juego y la embriaguez son los azotes que las están degenerando rápidamente” (160).

Por otro lado, las fuentes documentales referidas a las prácticas alimentarias en los contextos mineros son escasas. Hasta el momento solo contamos con algunos datos hallados en las obras de Haigh ([1831] 1920), Vicuña (1856), Lallemant (1890) y el II Censo de la República Argentina de 1895. Para empezar, esta documentación permite observar que la fauna autóctona era abundante: "en el Paramillo vimos numerosas tropillas de guanacos que en invierno bajan siempre a los valles y cerros más bajos” (Haigh [1831] 1920, 56). Es posible que los ocupantes de los emplazamientos mineros que tenían o podían acceder a armas de fuego hayan cazado esta fauna, ya que aun para los viajeros era una actividad común: "para divertirnos y matar las horas convenimos en tomar alternativamente la escopeta y salir en busca de guanacos” (Haigh [1831] 1920, 56). También, existen datos que señalan la existencia de actores especializados en esta tarea, quienes luego vendían la carne en los emplazamientos mineros. En este sentido, otro viajero observó:

[...] los guanacos andan en tropillas de 8 o 10 jeneralmente [...] Los arrieros los cazan con perros i las bolas, i hai hombres que viven de la caza de estos animales que se hace por partidas de 8 o 10 personas que llevan al menos un centenar de perros i las mulas necesarias para cargar los cueros i la carne de las reses que matan. Del cuero hacen excelentes lazos, principalmente del pescuezo, i la carne la venden a los mineros de Uspallata a 4 reales la arroba, pues es casi tan sabrosa aunque no tan alimenticia como la de vaca. (Vicuña 1856, 448)

Dicha observación fue confirmada el 10 de mayo de 1895 cuando se censaron las 250 personas que habitaban en los Paramillos de Uspallata. En este censo se consignó "qué profesión, oficio, ocupación o medio de vida tiene” la persona encuestada. Allí se reconoció la presencia de nueve arrieros quienes seguramente cumplían la función de abastecimiento a los emplazamientos mineros de carne de fauna autóctona, entre otros productos (II Censo de la República Argentina 1895).

El acceso a otros productos alimenticios de distribución regional, y especialmente la forma en que estos eran racionados entre los trabajadores mineros de los Paramillos de Uspallata, es evidenciado en otra cita: 
[...] en 3/4 kilógramos carne de vaca; 1 libra de pan; 1 libra de papas, ó de maíz, ó de arroz, ó de trigo; 12 onzas de sal por semana. La carne se entiende que sea pulpa, siendo con huesos, se aumenta algo más el peso de la ración. (Lallemant 1890, 63)

El censo referido menciona la presencia de un “despensero", lo que sugiere que dicho racionamiento era impartido por la propia empresa (II Censo de la República Argentina 1895, tomo 30, ff. 164-165).

Otro indicio para tener en cuenta es la disponibilidad de agua en el área de los Paramillos de Uspallata, respecto a la cual el ingeniero Lallemant nos confirma que era obtenida de las minas, y que tenía ciertas propiedades: “[...] el agua de las minas es muy buena, sin gusto ni carácter excepcional. Es muy dura, y da fuertes incrustaciones en la caldera, que son principalmente de sulfato de cal". Asimismo, aporta datos que refieren a las dificultades para la cocción de ciertos alimentos: "Imposible es en el Paramillo de cocinar garbanzos, porotos y en general fabáceas ó leguminosas á un punto de blandura suficiente, en olla ordinaria; se explica esto porque el agua hierve á $90^{\circ} 89$ centígrados en el Paramillo [...]" (Lallemant 1890, 49). Dicha dificultad puede relacionarse con las condiciones de baja presión atmosférica vinculada a la altitud sobre el nivel del mar de este emplazamiento. En el mismo sentido debe considerarse la limitada disponibilidad de leña con relación a la demanda de las ocupaciones mineras en la zona (Mafferra, Chiavazza y Roig 2019; Sironi 2013b).

Con respecto a la actividad de procesar y preparar alimentos, el censo revela la presencia de una cocinera y un mayordomo, lo que sugiere una división del trabajo que implica que al menos algunos actores estuvieron liberados de esta tarea cotidiana. Sin embargo, ese beneficio era reservado solo a una porción mínima de esta población. En el mismo sentido, la mención de dos propietarios y dos capataces hace referencia a la concentración de la propiedad y el liderazgo en esta población. Al igual que en el caso de la presencia de una cocinera, el censado de un mayordomo también puede relacionarse con la existencia de estas asimetrías. En lo que tiene que ver con la división del trabajo, evidente en las ocupaciones consignadas en el censo, es significativa la presencia de un agricultor, especialmente en razón de las limitantes planteadas por las condiciones biogeográficas de los asentamientos en los Paramillos de Uspallata (II Censo de la República Argentina 1895, tomo 30, ff. 164-165). 


\section{Resultados del análisis de la cadena operativa y escala de distribución}

Procurando integrar los resultados obtenidos en las diversas líneas de evidencia material presentadas, observaremos ahora cómo se expresan estos datos en relación con las categorías que propusimos evaluar. Es decir, analizaremos de qué modo se reflejan las materialidades en las diferentes fases de la cadena operativa (tabla 8) y en las escalas de distribución propuestas (tabla 9), sumando los aportes hallados en el registro documental.

En la tabla 8 pueden observarse las tendencias generales en cuanto a la cadena operativa. Para ambos sitios las etapas de obtención y preparación se ven subrepresentadas. Por su parte, en el sitio MPS las fases de distribución ( $=9)$ y consumo ( $\mathrm{N}=7)$ son las que cuentan con más tipos de artefactos asociados, mientras que para el caso de MLA, casi todas las evidencias corresponden a la etapa de distribución representada por ocho tipos de artefactos asociados.

En relación con la fase de obtención de alimentos, las evidencias presentes se asocian a la práctica de caza. La limitada variedad de objetos vinculados a dicha fase sugiere que los alimentos no fueron producidos en los sitios. Esto, sumado a lo aportado por la información documental, señala la importancia de los arrieros identificados como los actores especializados en el abasto de alimentos, aunque aún no es clara su vinculación estable o eventual con los emplazamientos.

La no producción de los alimentos en los sitios es reforzada por la especial representatividad de los objetos en la fase de distribución. Por su parte, la baja diversidad de objetos relacionados con la fase de preparación indica que gran parte de los suministros que llegaron a los sitios fueron consumidos luego de procesos que incluyeron escasos objetos vinculados a labores de preparación o transformación de alimentos.

La tabla 8 permite observar también una clara distinción entre ambos sitios, dada por la mayor cantidad de tipos de artefactos de consumo presentes en MPS, y no así en MLA. Esta distinción se explica a partir de la permanente ocupación de la comunidad minera de MPS, a diferencia de MLA, donde los trabajadores no habitaban en el lugar del emplazamiento, tal vez por la relativa cercanía a la ciudad de Mendoza del sitio MLA con respecto a MPS (Sironi 2015a). 


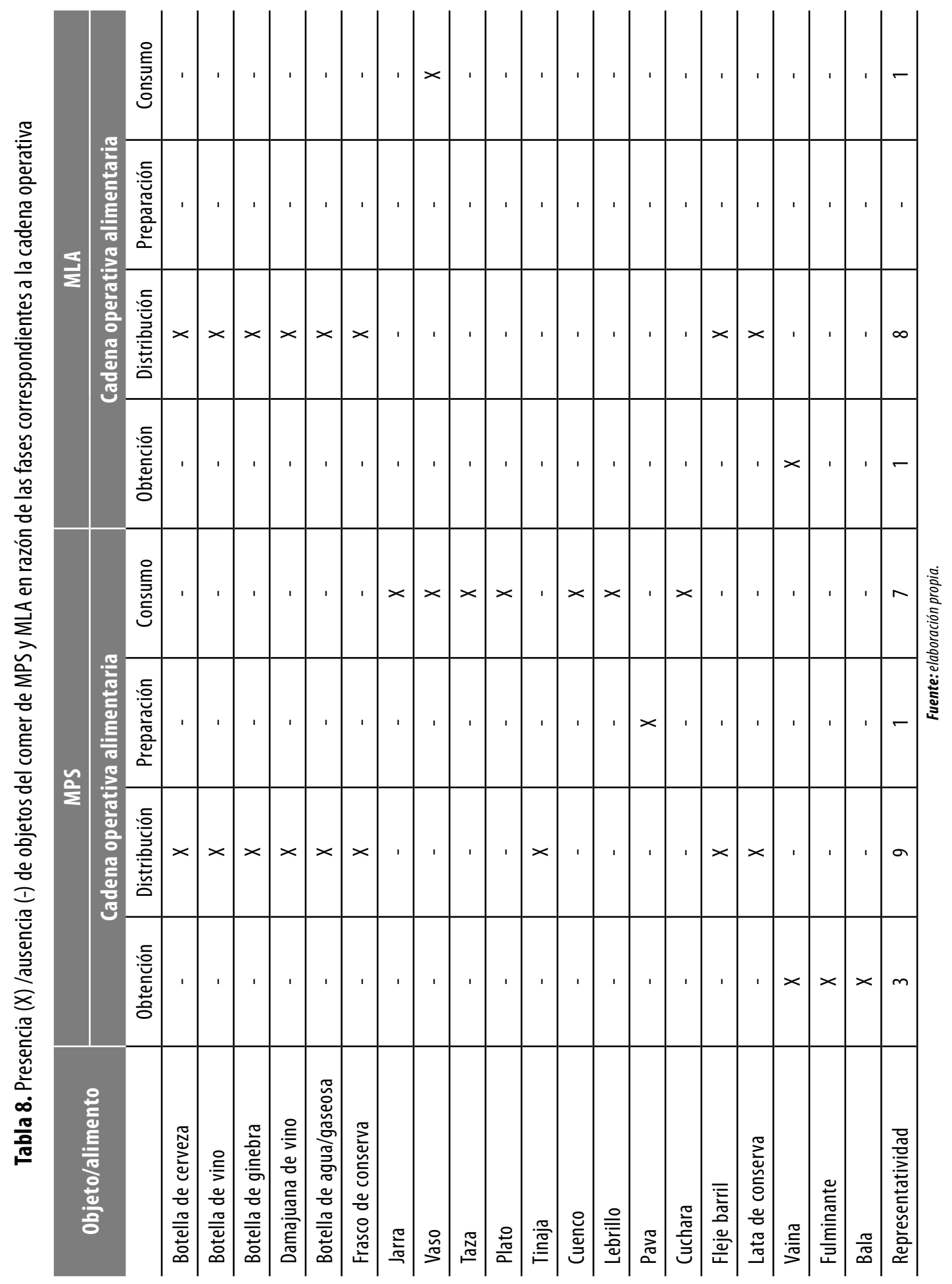


En ambos sitios la baja presencia de tipos de objetos relacionados con la fase de preparación quizás revele que algunos vinculados a la distribución eran reutilizados en esta fase, en particular, los recipientes de metal - como las latas de conserva - que pueden haber sido empleados para cocinar o simplemente para calentar. Sin embargo, entre los materiales hallados no encontramos marcas de tizne u otras de termoalteración que permitan confirmar esta propuesta. Para ambos sitios, y especialmente para MLA, los artefactos asociados a la distribución pueden haber servido también para el consumo directo, aspecto que discutiremos cuando abordemos la escala de distribución intrasitio.

En ese sentido, en la tabla 9 puede observarse el resultado de la diversidad de objetos del comer y productos alimenticios presentes en función de las escalas de distribución, relacionadas con el aprovisionamiento de los alimentos, es decir, con las escalas global, regional y local, y luego, con la escala intrasitio, la cual se vincula al racionamiento y distribución de la comida entre los habitantes de los emplazamientos mineros. Observamos que ambos sitios estuvieron en especial conectados a la escala regional de distribución de alimentos. Esto se debe a que los emplazamientos, y específicamente MPS, a pesar de su ubicación periférica, se encontraban próximos a las rutas comerciales que vinculaban el tramo Atlántico-Pacífico y las rutas andinas que conectaban el norte con el centro del país. Estas rutas comerciales permitían también la llegada de productos que circulaban a escala global. Este circuito encontró su apogeo a partir del acelerado proceso de liberalización del territorio económico experimentado durante nuestro periodo de estudio. 


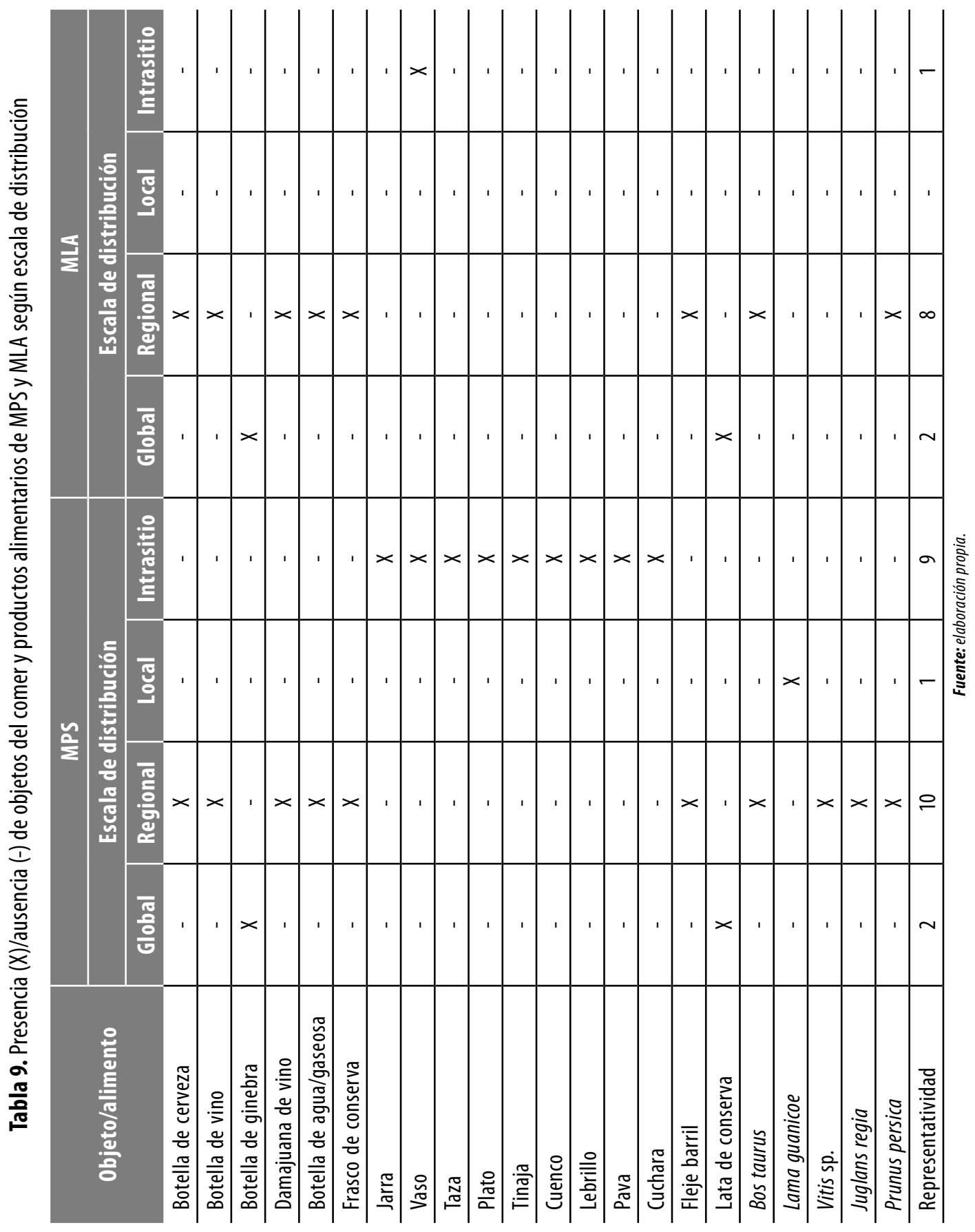


Si bien esta escala está representada solo por dos elementos (latas de conserva y botellas de ginebra), ambos fueron característicos del tipo de alimentación asociada a los emprendimientos mineros. Por otro lado, reafirmando lo observado en el análisis de la cadena operativa, los alimentos obtenidos en la escala local están ausentes en MLA o solo están representados por un elemento en MPS, lo que da cuenta del alto alcance de la división social del trabajo en este contexto. En lo que se refiere a los objetos que intervinieron en la distribución y el racionamiento de los alimentos hacia adentro del sitio - como pudimos observar antes en la fase de consumo de la cadena operativa-, la diferencia entre ambos sitios es notable ya que los tipos de objetos presentes en MPS son numerosos mientras que solo uno de ellos se registra en MLA. Esto, como ya indicamos, se relaciona con que los ocupantes de MPS vivían en el área doméstico-productiva, mientras que los trabajadores de MLA se restringían a la ocupación durante su jornada laboral.

Siguiendo la propuesta analítica de Mafferra, Sironi y López (2012), estos objetos sostienen una lógica de distribución de los alimentos entre las personas, que contribuye a delimitar los gestos y prácticas permitidas durante el consumo de los alimentos. Dentro de los objetos presentes en MPS vemos uno relacionado con la distribución colectiva, como la tinaja; otros destinados a distribuir alimentos y bebidas entre grupos más pequeños, como la jarra, el lebrillo o la pava o caldera ${ }^{5}$; otros que definieron porciones por persona, como vaso, taza, plato y cuenco, y, por último, uno relacionado con el ordenamiento de los gestos de consumo de una persona en el momento de comer, tal como la cuchara.

Debemos comprender también que varios objetos del comer relacionados con escalas de distribución más amplia —como las botellas y las latas-, si bien eran distribuidos de forma masiva, racionalizaban una distribución menor, determinando porciones destinadas a grupos pequeños o incluso a consumidores individuales. Así, estos objetos desplazaban su función primera de contener, conservar y distribuir alimentos a escalas global y regional, a la de racionalizar el consumo dentro de los emplazamientos, lo cual debió resultar significativo en sitios como MLA donde solo se presentó un tipo de objeto relacionado con el consumo o la escala de distribución intrasitio.

5 Una tinaja es una vasija de gran tamaño de barro cocido, utilizada generalmente para conservar líquidos. El lebrillo es un recipiente cuya boca es ligeramente mayor que su base, de forma elíptica; su largo suele rondar los $40 \mathrm{~cm}$. La pava o caldera es una jarra de metal utilizada para calentar y distribuir líquido, generalmente de entre 1 y 2 litros de capacidad. 


\section{Discusión y conclusiones}

Propusimos abordar la alimentación desde una perspectiva que analice de forma integral las fuentes materiales y documentales asociadas a dos sitios mineros. Para lograrlo, presentamos primero los resultados obtenidos en cada una de las líneas de análisis de los materiales vinculados al fenómeno alimentario. Luego, desarrollamos una interpretación a partir del análisis de dos categorías propuestas para este caso. Estas evaluaron, por un lado, la cantidad de tipos de objetos presentes en cada sitio en relación con las fases de la cadena operativa alimentaria; y, por otro lado, la diversidad de objetos presentes en razón de diferentes escalas de distribución asociadas a los alimentos que se consumieron durante la ocupación. La propuesta de análisis aplicada nos permitió observar tendencias que a priori no podrían diferenciarse en el análisis particular de cada uno de los materiales, a pesar de ser conscientes de que tal análisis puede subsumir diferencias cuantitativas entre los diversos tipos de objetos presentes.

El examen de la cadena operativa fue útil para detectar que los tipos de objetos asociados a las etapas de obtención y preparación estuvieron subrepresentados en ambos sitios. Esto quizá refleje el hecho de que gran parte de los actores que habitaron los emplazamientos estuvieron dedicados exclusivamente al trabajo minero. De igual modo, la evidencia documental nos permitió identificar algunos actores relevantes en dichas etapas. Con respecto a la obtención de alimentos, la figura de los arrieros sobresalió por su importancia en el abasto de carne en los emplazamientos (posiblemente también de otros productos, aunque estos no se mencionan en la documentación). Los datos históricos, así como el análisis de los restos arqueozoológicos, permitieron confirmar la presencia de carne bovina para ambos sitios y también de fauna autóctona, para el caso de MPS. La importancia que tuvo la caza de guanacos para el sostenimiento de estos emprendimientos mineros es un dato interesante que muestra la interconexión de economías extractivas diversas que a priori no suelen vincularse. Una investigación más profunda sobre el papel de los arrieros en este contexto podría resultar significativa para comprender su importancia en las redes locales de intercambio y los modos en que estos se vincularon con los emprendimientos mineros. La documentación permitió identificar además otro actor relacionado con el abastecimiento, como el "despensero". Asimismo, los datos observados en Lallemant (1890) indican que dicho abastecimiento estaba claramente regulado y normativizado, ya que se fijaban de manera detallada las raciones semanales de los distintos alimentos destinados a los trabajadores mineros. 
Con respecto a la fase de preparación de los alimentos observamos que la baja diversidad de objetos relacionados con esta actividad pudo deberse a dos fenómenos: a un tipo de alimentación que se componía de comidas que arribaban a los emplazamientos mineros listas para su consumo o a que la preparación de los alimentos era una práctica realizada de forma centralizada. Para el caso de MLA, la ausencia de objetos relacionados con la fase de consumo indica que pudo tratarse del primer fenómeno. Para el MPS, datos censales históricos que revelan la presencia de una cocinera y un mayordomo, así como el reconocimiento de un horno abovedado en uno de los recintos domésticos (Sironi 2015a), sugieren que en este emplazamiento pudo darse también el segundo fenómeno. No obstante, la existencia de solo dos personas especializadas en estas tareas para una población de 250 habitantes hace pensar que dichas labores estaban restringidas al servicio de los propietarios y capataces del emplazamiento minero - y sus respectivas familias identificadas también en la documentación-.

Es interesante destacar que en los contextos analizados, que se encuentran conectados a rutas comerciales regionales, los objetos del comer y los contenedores de alimentos distribuyen productos que son elaborados a gran escala, lo que evidencia tipos de consumo asociados a la emergencia de estándares globales. Estos estándares dieron paso a materialidades que racionalizaron un nuevo tipo de consumo centrado en el actor individual, ya que los elementos que los demuestran (latas de conserva y botellas de ginebra) fueron representativos del tipo de alimentación de las poblaciones mineras locales. Se propone que esto se correlaciona con el surgimiento del sentido moderno del gusto, las formas de distinción social y la estructuración de jerarquías sociales posrevolucionarias (Flandrin 1999), cuando la alimentación se incluye en nuevas modalidades de consumo que ponen el acento en el individuo. Dicha tendencia ha sido reconocida en el análisis de la cultura material culinaria asociada a contextos históricos poscoloniales (Mafferra, Sironi y López 2012; Marschoff 2010; Sironi, Mafferra y López 2016).

Como conclusión, estos resultados pueden constituirse en una plataforma que nos permita indagar en la integración de diversas líneas de evidencia material (registros contables mineros, crónicas de viajeros, relatos etnográficos, entre otros) y establecer sus relaciones contextuales, con el objetivo de alcanzar una modelización de los contextos domésticos en sitios de gran complejidad, como es el caso de las explotaciones mineras. La interacción de estas líneas de análisis permitirá aproximarnos a la reconstrucción de patrones de comensalismo. En especial, estos resultan de interés en el contexto de estudios de Argentina de fines del siglo XIX y principios del XX, donde el auge inmigratorio manifiesta 
fricciones ideológicas y culturales que permiten la consolidación de los procesos de etnogénesis que se constatan, entre otros factores, en la diversidad de prácticas culinarias y consumos de productos alimenticios.

\section{Referencias}

\section{Fuentes primarias}

Archivo de la Dirección de Minas de la Provincia de Mendoza (ADMPM)

Expediente 928-S-1917. “Mina La Atala”, s. f.

Expediente 748-T-1939. “Minas Paramillos Sur”, s. f.

Segundo Censo de la República Argentina. 1895. "Provincia de Mendoza, Departamento de Las Heras, Distrito Paramillos de Uspallata”, t. 30, ff. 164-165.

\section{Fuentes secundarias}

Abraham, Elena. 2000. “Geomorfología de la provincia de Mendoza”. En Argentina. Recursos y problemas ambientales de las zonas áridas, t. 1, editado por Elena Abraham y Francisco Rodríguez Martínez, 29-48. Granada, Mendoza: GTZ/IDR; Iadiza.

Araújo, Emiliano. 2016. "Modos de comer y culturas en transición. Análisis arqueofaunístico de un contexto doméstico de los siglos XV-XVI de la ciudad de Mendoza (Punto Arqueológico Ruinas de San Francisco)”. Tesis de Licenciatura en Historia con orientación en Arqueología, Facultad de Filosofía y Letras, Universidad Nacional de Cuyo, Mendoza.

Babot, María del Pilar, María Marschoff y Francisco Pazzarelli, eds. 2012. Las manos en la masa. Arqueologías, antropologías e historias de la alimentación en Suramérica. Córdoba: Universidad Nacional de Córdoba.

Baudrillard, Jean. 1995. El sistema de los objetos. Ciudad de México: Siglo XXI.

Bialet Massé, Juan. 1904. Informe sobre el estado de las clases obreras argentinas en el interior de la República, t. III. Buenos Aires: Adolfo Grau.

Bulmer, Martin. 1975. "Sociological Models of the Mining Community”. Sociological Review 23 (1): 61-92. https://doi.org/10.1111/j.1467-954X.1975.tb00518.x

Buxó, Ramón. 1997. Arqueología de las plantas. Barcelona: Crítica.

Castillo, Leonardo, Emiliano Araújo, Horacio Chiavazza y Cristina Prieto Olavarría. 2018. "Cocinar y alimentarse en tiempos de conquista. Reconstruyendo paquetes culinarios a partir de análisis cerámicos y arqueofaunísticos (Mendoza, siglos XV-XVII)”. Arqueología 24 (2): 109-132. http://revistascientificas.filo.uba.ar/index.php/Arqueologia/ article/view/5003 
Chiavazza, Horacio. 2012. "Arqueología del trabajo y los trabajadores: contextos productivos del siglo XIX en las márgenes del capitalismo (Mendoza, Argentina)”. En Actas del XVIII Congreso Nacional de Arqueología Chilena, editado por Sociedad Chilena de Arqueología, 369-380. Santiago de Chile: Sociedad Chilena de Arqueología.

Cueto, Adolfo. 2003. Minería e impacto en Mendoza. Mendoza: Universidad Nacional de Cuyo.

Douglas, Mary. 1997. “Deciphering a Meal”. En Food and Culture: A Reader, editado por Carole Counihan y Penny van Esterik, 36-54. Nueva York: Routledge.

Estrella, Diego y Alejandra Gasco. 2002. “Registro óseo de las Minas de Paramillos”. En

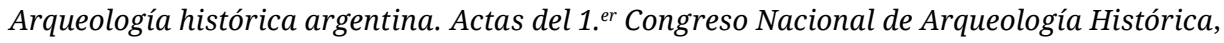
821-829. Mendoza: Corregidor.

Flandrin, Jean Louis. 1999. "From Dietetics to Gastronomy: The Liberation of the Gourmet". En Food: A Culinary from Antiquity to the Present, editado por Jean Louis Flandrin y Massimo Montanari, 418-432. Nueva York: Columbia University Press.

Goody, Jack. 1995. Cocina, cuisine y clase. Estudio de sociología comparada. Barcelona: Gedisa.

Haigh, Samuel. (1831) 1920. Bosquejos de Buenos Aires, Chile y Perú. Buenos Aires: La Cultura Argentina.

Juan, Juan. 2004. “Mendoza”. En Historia de la minería argentina, t. II, editado por Eddy Lavandaio y Edmundo Catalano, 175-203. Buenos Aires: Segemar.

Knapp, Bernard. 1998. "Social Approaches to the Archaeology and Anthropology of Mining”. En Social Approaches to an Industrial Past, editado por Bernard Knapp, Vincent Pigott y Eugenia Herbert, 136-158. Londres: Routledge.

Labarca, Rafael. 2009. "La comida en la pampa durante el auge salitrero en Chile: una visión desde la zooarqueología histórica”. Revista Española de Antropología Americana 39 (2): 101-114. https://revistas.ucm.es/index.php/REAA/article/view/REAA0909220101A

Labarca, Rafael, Elisa Calás y Francisco Rivera. 2010. “Solteros o casados: ¿quién come mejor? La evidencia faunística del asentamiento minero histórico de Capote (región de Atacama, Chile)”. Estudios Atacameños 39: 21-34. http://www.oalib.com/paper/2876550\#. XKvUGlVKjIU

Lallemant, Germán. 1890. La minería en la provincia de Mendoza: el Paramillo de Uspallata. Buenos Aires: Coni.

Lema, Carolina. 2015. "Breve nota sobre las mayólicas y cerámicas de tradición europea recuperadas en el mineral de Incahuasi (Catamarca, Argentina)”. Revista de Arqueología Histórica Argentina y Latinoamericana 9 (1): 71-88.

Lemonnier, Pierre. 1986. "The Study of Material Culture Today: Towards an Anthropology of Technical Systems”. Journal of Anthropological Archaeology 5: 147-186.

Lévi-Strauss, Claude. 1968. "El triángulo culinario”. En Lévi-Strauss: estructuralismo y dialéctica, compilado por Bernard Pingaud, Luc de Heusch y Claude Lévi-Strauss, 39-57. Buenos Aires: Paidós.

Mafferra, Luis, Osvaldo Sironi y Manuel López. 2012. “Objetos del comer y prácticas de distribución y consumo en la ciudad de Mendoza”. En Actas del V Congreso Nacional 
de Arqueología Histórica, vol. I, editado por Eduardo Rodríguez Leirado y Daniel Schávelzon, 354-367. Saarbrücken: Editorial Académica Española.

Mafferra, Luis, Horacio Chiavazza y Fidel Roig Juñent. 2019. “The Impact of Mining on the Woody Vegetation from the Southern Andes: An Anthracological Study from the Andean Precordillera in the Central Western Argentina (XVIII-XIX Centuries)”. Vegetation History and Archaeobotany: 65-79. DOI: 10.1007 / s00334-018-0681-z

Marschoff, María. 2010. "Sociabilidad y alimentación. Estudio de casos en la transición al siglo XIX en el Virreinato del Río de la Plata”. En South American Archeology Series, editado por Andrés Izeta, 35-49. Oxford: Archaeopress.

—. 2011. "Sociabilidad y alimentación. Estudio de casos en la transición hacia el siglo XIX en el Virreinato de La Plata”. Arqueología 17: 291-297.

-. 2013. "Los objetos de la alimentación en el Buenos Aires virreinal: entre el mercado mundial y las prácticas cotidianas”. Revista de Arqueología Histórica Argentina y Latinoamericana 7 : 11-40.

-. 2014. "La sociedad virreinal en Buenos Aires: un análisis desde la cultura material y la alimentación”. Revista de Indias 74 (260): 67-100. http://revistadeindias.revistas.csic.es/index. php/revistadeindias/article/view/949/1023

Mengoni Goñalons, Guillermo. 2010. “Zooarqueología en la práctica: algunos temas metodológicos”. Xama 19-23: 83-113.

“La minería”. 1921. Diario Los Andes (Mendoza). Número especial: Vistazo retrospectivo a la región de Cuyo al cerrar el año 1920, 97-112.

Pazzarelli, Francisco. 2008. "Notas acerca de una arqueología de la comida”. La Zaranda de Ideas 4: 157-162.

—. 2010. “La importancia de hervir la sopa. Mujeres y técnicas culinarias en los Andes”. Antípoda 10: 157-181. https://revistas.uniandes.edu.co/doi/abs/10.7440/antipoda10.2010.08

Pollock, Susan. 2015. Between Feasts and Daily Meals. Towards an Archaeology of Commensal Spaces. Berlín: Topoi.

Prieto, María del Rosario. 2007. "Variaciones y anomalías climáticas y su impacto socioeconómico en Mendoza en los últimos 500 años”. En Mendoza, identidad, educación y ciencias, compilado por Arturo Roig y María Cristina Satlari, 605-654. Mendoza: Ediciones Culturales de Mendoza.

Puebla, Lorena, Valeria Zorrilla y Horacio Chiavazza. 2005. “Análisis del material cerámico histórico del predio mercedario de la ciudad de Mendoza”. En Arqueología en el predio mercedario de la ciudad de Mendoza, editado por Horacio Chiavazza y Valeria Zorrilla, 157-217. Mendoza: Editorial de la Universidad Nacional de Cuyo.

Quiroga, Marcos. 2005. "Estudios de los metales arqueológicos del predio mercedario de Mendoza”. En Arqueología en el predio mercedario de la ciudad de Mendoza, editado por Horacio Chiavazza y Valeria Zorrilla, 271-293. Mendoza: Editorial de la Universidad Nacional de Cuyo.

Santos Martínez, Pedro. 1961. Historia económica de Mendoza durante el Virreinato (17761810). Madrid: Consejo Superior de Investigaciones Científicas. 
Schávelzon, Daniel. 2000. Historias del comer y del beber en Buenos Aires. Arqueología histórica de la vajilla de mesa. Buenos Aires: Aguilar.

Sironi, Osvaldo. 2013a. Entre bebidas y medicinas: el uso del vidrio entre los mineros de Los Hornillos (Mendoza, Argentina). Mendoza: Editorial de la Universidad Nacional de Cuyo.

-. 2013b. "El impacto de los medios de producción minera en los Paramillos de Uspallata (Mendoza, Argentina): un acercamiento histórico en la larga duración (siglos XVII-XIX)”. Revista de Historia Americana y Argentina 48 (1): 57-97.

-. 2015a. "Intervenciones arqueológicas en el sitio Minas Paramillos Sur (Reserva Natural Villavicencio, Mendoza)”. En Arqueología y etnohistoria del centro oeste argentino: aportes desde las $V$ Jornadas Arqueológicas Cuyanas, editado por Joaquín Roberto Bárcena, 119-133. Mendoza: Xama Series Monográficas.

-. 2015b. "Arqueología histórica industrial: explotaciones mineras en el noroeste de Mendoza”. Tesis doctoral, Facultad de Filosofía y Humanidades, Universidad Nacional de Córdoba.

—. 2016. "Arqueología histórica industrial: explotaciones mineras en el noroeste de Mendoza”. Tesis de doctorado, Facultad de Filosofía y Humanidades de la Universidad Nacional de Córdoba, Argentina.

-. 2017. "Estudio arqueohistórico del registro vítreo en sitios mineros (Mendoza, Argentina)". Arqueología Iberoamericana 34: 3-8.

-. 2018. “Arqueología industrial en Mina 'La Atala' (Reserva Natural Divisadero Largo, Mendoza)”. Revista de Arqueología Histórica Argentina y Latinoamericana 12: 832-861.

-. 2019. "Mining Ways of Life in the Southern Andes: Historical Anthropological Archaeology in Mendoza, Argentina”. International Journal of Historical Archaeology 23 (1): 153-171.

Sironi, Osvaldo, Luis Mafferra y Manuel López. 2016. “Una perspectiva arqueológica de los modos del comer en el predio mercedario de Mendoza”. Anuario de Arqueología 8: 185-199.

Sironi, Osvaldo, Emiliano Araújo, Manuel López y Marcos Quiroga. 2013. "Arqueozoología de un contexto minero: Minas Paramillos Sur (Mendoza, Argentina)”. Comechingonia Virtual VII (2): 189-215.

Vicuña Mackenna, Benjamín. 1856. Pájinas de mi diario durante tres años de viajes 18531854-1855. Santiago: Imprenta del Ferrocarril. 